\title{
Spontaneous resolution of hydrops fetalis due to nonfatal fetal renal vein thrombosis
}

\author{
Small M*, Ellestad $S$ and James AH \\ Division of Maternal Fetal Medicine, Duke University School of Medicine, USA
}

\begin{abstract}
46yo G6P3114 was admitted to the labor ward at 24 weeks gestation for preterm labor. She had a normal midtrimester anatomic survey and declined aneuploidy screening or karyotype determination. At 27 weeks, follow up ultrasound demonstrated an enlarged echogenic right fetal kidney, abdominal ascites and unilateral pleural effusion. The inferior vena cava (IVC) had echogenic borders and appeared compressed by the right kidney. The amniotic fluid volume was normal. Hydrops resolved at 28 weeks gestation. She remained hospitalized and at 31 weeks gestation spontaneously delivered a male infant weighing 1590 g. Postnatal imaging revealed a right, renal vein thrombosis extending to the inferior vena cava (IVC). No anticoagulation was administered, due to the infant's prematurity and risk for germinal matrix hemorrhage.
\end{abstract}

At 7 months of age, the neonate met all developmental milestones. He had negative thrombophilia screening, resolution of the right renal vein thrombosis, a patent IVC, and normal renal function. This case demonstrates an unusual presentation of reversible fetal hydrops and renal vein and IVC thrombosis of unknown etiology.

\section{Case report}

A 46-year-old G6 P3114 with a history of a previous preterm delivery at 26 weeks gestation was admitted to the labor and delivery unit at 24 weeks gestation following sonographic and clinical findings of no measurable cervical length and membranes prolapsing through a $2 \mathrm{~cm}$ dilated external cervical os. She had had a normal midtrimester anatomic survey and had declined both invasive and noninvasive testing for fetal karyotype determination.

At 27 weeks, a follow-up ultrasound demonstrated an enlarged and echogenic right fetal kidney, measuring $4.7 \mathrm{~cm}$ in length (Figure 1). Fetal abdominal ascites and unilateral pleural effusion were noted at that time, consistent with hydrops. The inferior vena cava (IVC) demonstrated echogenic borders and appeared to be compressed by the right kidney (Figures $2 \mathrm{a}$ and $2 \mathrm{~b}$ ). Flow to the right renal artery was interrupted. The amniotic fluid volume was normal. Fetal biometry was symmetric with an estimated fetal weight of 1169 grams $\left(75^{\text {th }}\right.$ percentile); abdominal circumference was $24.6 \mathrm{~cm}$ (89.7th percentile). The hydrops resolved at 28 weeks gestation (Figures 3 and 4).

She remained hospitalized. At 31 weeks gestation, she experienced preterm labor and vaginally delivered a male infant weighing $1590 \mathrm{~g}$. The infant's Apgar scores at birth were 8 at 1 minute and 9 at 5 minutes.

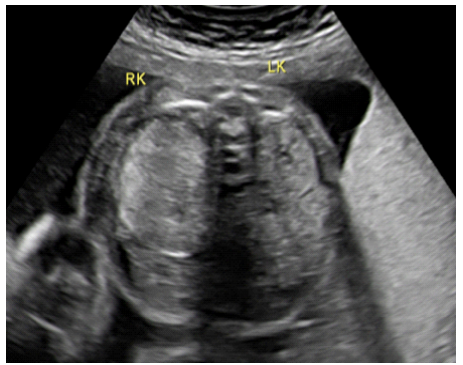

Figure 1. Enlarged right kidney (arrow) at 27 weeks gestation.
Postnatal imaging demonstrated a right RVT thrombosis extending to the IVC. Due to the infant's prematurity and risk for germinal matrix hemorrhage, no anticoagulation was administered.

At 7 months of age, he met all developmental milestones. His subsequent evaluations demonstrated negative thrombophilia screening, resolution of the RVT, a patent IVC, and normal renal function.

\section{Discussion}

Neonatal renal vein thrombosis (RVT) is rare, affecting $0.5 / 1000$ live births [1]. The condition is associated with a poor prognosis secondary to morbidity from chronic renal disease and/or hypertension [2,3]. RVT is typically diagnosed in neonates following clinical detection of a

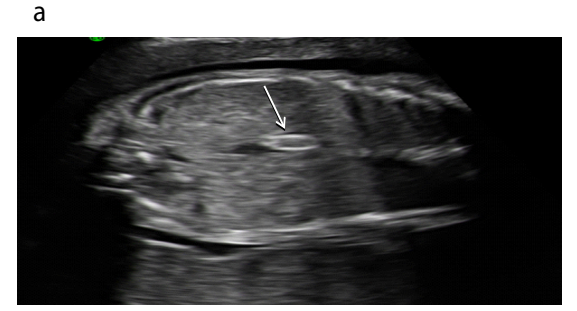

Figures 2. a and b. Echogenic inferior vena cava (arrow),due to thrombus at 27 weeks gestation. b

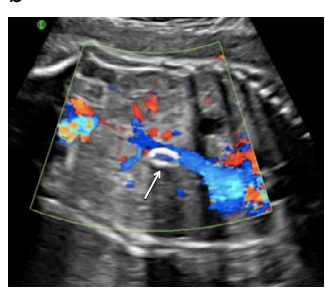

Correspondence to: Small M, Division of Maternal Fetal Medicine, Duke University School of Medicine, DUMC 3967, USA, Tel: 919-668-0843; Fax: 919681-7861; E-mail: maria.small@duke.edu

Key words: fetal renal vein thrombosis, hydrops fetalis, prenatal diagnosis

Received: December 12, 2015; Accepted: January 09, 2016; Published: January 13,2016 
Table 1. HydropsFetalis associated with Renal Vein Thrombosis, Published Cases.

\begin{tabular}{|c|c|c|c|c|c|}
\hline Author & Description & $\begin{array}{l}\text { Gestational Age and Mode } \\
\text { of Delivery }\end{array}$ & Thrombophilia & Infection & Postnatal Outcome* \\
\hline Van Der Vange, 1986 [6] & $\begin{array}{l}\text { Bilateral Renal Vein Thromboses } \\
\text { Extending to IVC* }\end{array}$ & $\begin{array}{l}25 \text { weeks, vaginal } \\
\text { (Induced) }\end{array}$ & Unknown & & $\begin{array}{l}\text { Intrauterine Fetal Demise } \\
\text { (IUFD) }\end{array}$ \\
\hline $\begin{array}{l}\text { Patel, } \\
1988[7]\end{array}$ & $\begin{array}{l}\text { Bilateral Renal Vein Thromboses } \\
\text { Extending to IVC* }\end{array}$ & $\begin{array}{l}30 \text { weeks, cesarean section } \\
\left(C D^{* *}\right)\end{array}$ & Unknown & + Acute CMV antibody & Neonatal death \\
\hline $\begin{array}{l}\text { Hage, } \\
1994[8]\end{array}$ & Left Renal Vein Thrombosis & 31 weeks, $(\mathrm{CD})$ & $\begin{array}{l}\text { Maternal Antiphospholipid Antibody } \\
\text { Syndrome }\end{array}$ & & $\begin{array}{l}\text { Neonatal death, pulmonary } \\
\text { hypoplasia }\end{array}$ \\
\hline Smorgick, 2007 [4] & $\begin{array}{l}\text { Bilateral RVT Extending to } \\
\text { IVC*, Cerebral Intraventricular } \\
\text { Hemorrhage }\end{array}$ & 27 weeks, (CD) & Negative thrombophilia testing & & $\begin{array}{l}\text { Neonatal death, day } 10 \text { of } \\
\text { life from multiorgan system } \\
\text { failure }\end{array}$ \\
\hline Current Case & Right RVT Extending to IVC* & 31 weeks, (Vaginal) & Negative thrombophilia testing & & Survival \\
\hline
\end{tabular}

${ }^{*} \mathrm{IVC}=$ Inferior Vena Cava, $* * \mathrm{CD}=$ Cesarean Delivery

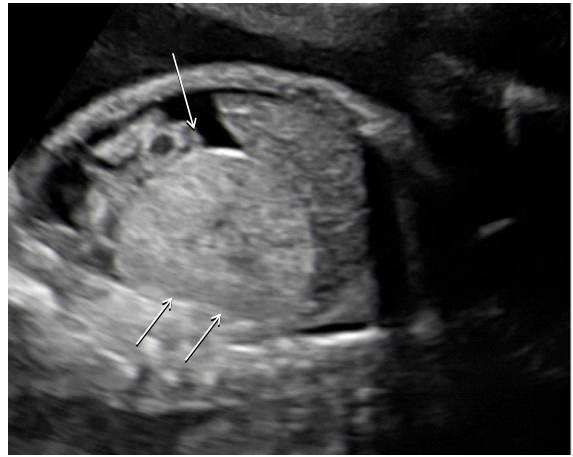

Figure 3. Abdominal ascites (arrow)and enlarged fetal right kidney (arrows) at 27 weeks gestation.

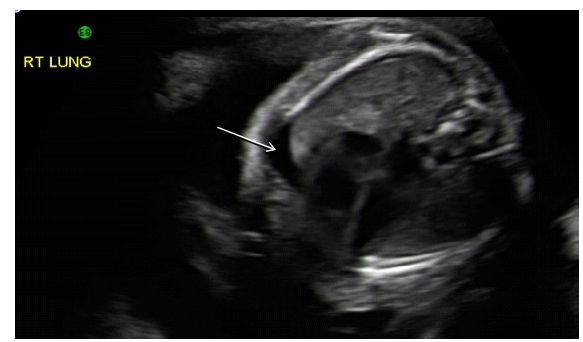

Figure 4. Right pleural effusion (arrow) at 27 weeks gestation.

one of the classic findings: hematuria, a palpable abdominal mass or thrombocytopenia [2].

The majority of cases of RVT are diagnosed within the first three days of life following evaluation for one of its clinical features [2], 26\% are diagnosed after the first three days of life, and only $7 \%$ of cases of RVT are diagnosed in-utero [2].

Smorgick reviewed the 11 cases of prenatally diagnosed RVT and/ or IVC thrombosis in the literature and identified hydrops fetalis in $33 \%$ of cases. RVT-associated hydrops fetalis was universally fatal [4].

Although there is no consensus on best treatment, anticoagulation is suggested for cases of bilateral RVT, although anticoagulation does not appear to reverse renal injury. In Lau's review of 271 cases, treatment ranged from supportive care $(40 \%)$ to heparin treatment (both low molecular weight and unfractionated heparin) in $43 \%$ of cases. Less common therapies included warfarin, fibrinolysis, antithrombin concentrate, and surgery. Lau et al. reported that $71 \%$ of neonates suffered permanent damage of the affected kidney and 3\% of children required transplant due to bilateral RVT. Mortality occurred in another 3\% of affected children and generally resulted from sepsis and multisystem organ failure [2].

Few cases of hydrops fetalis due to RVT are reported in the literature [5]. Of the 4 reported cases, all neonates died (Table 1) [4,68]. The present case represents the only surviving neonate with this condition. Like the other previously reported cases (range 25-31 weeks gestation) this neonate was also born preterm. The other reported cases were delivered by emergency cesarean due to worsening fetal testing. The only other vaginally delivered case occurred in the setting of a fetal demise. Unlike the other cases of RVT described in the literature, the neonate in the current case delivered following spontaneous, in-utero, resolution of the hydrops fetalis.

Although rare, RVT is the most common cause of thrombosis in the neonate $[3,9]$. Known risk factors for RVT are linked to hypercoagulability: hypovolemia/dehydration, asphyxia, polycythemia, congenital renal anomalies, maternal diabetes, umbilical catheters and procoagulant conditions (thrombophilia) $[2,3,10]$. Winyard et al. report on 24 patients presenting to a pediatric nephrology unit in the UK to quantify the rate of thrombophilic conditions and $44 \%$ of patients tested (8 of 18) demonstrated the presence of an inherited thrombophilia [9]. Dunn et al. proposed a mechanism for diabetesrelated infant thrombosis. Infants may experience 'water depletion, increased liver hematopoiesis and transfusion from an enlarged placenta" which may lead to polycythemia and hyperviscosity [11]. The investigators noted that thrombosis of renal and adrenal veins was 20 times more common in autopsies of infants born to diabetic mothers than to nondiabetic mothers [11].

Postnatal ultrasound imaging in RVT demonstrates echogenic kidneys with decreased corticomedullary differentiation. Calcifications may be visualized in the inferior vena cava. The kidney length may provide prognostic information, with larger kidneys conferring a less favorable prognosis $[9,12]$. In one series, none of the infants with renal size greater than $60 \mathrm{~mm}$ had normal renal function [9]. On Doppler analysis, renal veins may demonstrate increased resistance or absent flow.

The factors contributing to the spontaneous resolution of the fetal hydrops and the survival of this neonate are unknown. Rudolph reports a case of IVC thrombosis-associated fetal hydrops in which the 32-week neonate survived. One of the mechanisms contributing to neonatal survival in these scenarios may involve the development of in-utero collateral vessels [13]. Another contributing factor may be improved neonatal intensive care. The majority of cases of RVT were reported two decades ago. ICU technology has advanced since then. Anticoagulation, however, was not a factor on the present neonate's survival. The neonate in the present case was managed expectantly 
due to preterm status. This infant had normal renal function, platelet count, and negative thrombophilia testing. His postnatal course in the neonatal intensive care unit was unremarkable. The maternal thrombophilia status was not examined.

The present case demonstrates an unusual presentation of fetal hydrops and renal enlargement secondary to renal vein and IVC thrombosis of unknown etiology that resolved spontaneously without treatment, either in-utero or postnatally.

If fetal status is reassuring, expectant management of similar cases may be appropriate.

\section{References}

1. Schmidt B AM (1995) Neonatal Thrombosis report of a prospective Canadian and International Registry. Pediatrics 96: 939-943.

2. Lau KK, Stoffman JM, Williams S, McCusker P, Brandao L, et al. (2007) Neonatal renal vein thrombosis: review of the English-language literature between 1992 and 2006. Pediatrics 120: e1278-1284. [Crossref]

3. Kenet G, Nowak-Gottl U (2006) Fetal and neonatal thrombophilia. Obstet Gynecol Clin North Am 33: 457-466. [Crossref]

4. Smorgick N (2007) Prenatal thrombosis of the inferior vena cava and the renal veins. Prenat Diagn.27:603-607. [Crossref]
5. Malcomson RKJ (2007) Fetal Hydrops. In: Keeling WKT (Ed.), Fetal and Neonatology Pathology: Springer 878.

6. Van der Vange N BH, Bruinse HW (1986) Hydropsfetalis associated with inferior vena cava thrombois. Eur J Obstet Gynecol Reprod Biol 21: 113-115. [Crossref]

7. Patel RB, Connors JJ (1988) In utero sonographic findings in fetal renal vein thrombosis with calcifications. J Ultrasound Med 7: 349-352.

8. Hage ML, Liu R, Marcheschi DG, Bowie JD, Allen NB, et al. (1994) Fetal renal vein thrombosis, hydropsfetalis, and maternal lupus anticoagulant. A case report. Prenat Diagn 14: 873-877. [Crossref]

9. Winyard PJ, Bharucha T, De Bruyn R, Dillon MJ, van't Hoff W, et al. (2006) Perinatal renal venous thrombosis: presenting renal length predicts outcome. Arch Dis Child Fetal Neonatal Ed 91: F273-F278. [Crossref]

10. ZigmanA, Yazbeck S, Emil S, Nguyen L (2000) Renal vein thrombosis: a 10-year review. J pediatric surg 35:1540-1542. [Crossref]

11. Dunn V, Nixon GW, Jaffe RB, Condon VR (1981) Infants of diabetic mothers: radiographic manifestations. AJR Am J Roentgenol 137: 123-128. [Crossref]

12. Fishman JE, Joseph RC (1994) Renal vein thrombosis in utero: duplex sonography in diagnosis and follow-up. Pediatr Radiol 24: 135-136. [Crossref]

13. Rypens F, Avni F, Braude P, Matos C, Rodesch F, et al. (1993) Calcified inferior vena cava thrombus in a fetus: perinatal imaging. J Ultrasound Med 12: 55-58. [Crossref] 